\title{
The Effect of Body Posture Changes and Central Corneal Thickness on Intraocular Pressure among Healthy Malays
}

\author{
Nadiah RASHIDI, Md Muziman Syah MD MUSTAFA, \\ Norsham AHMAD, Megat Ahmad Fadhil MEGAT BASRI, \\ Nor Ariza MOHAMMAD and Firdaus YUSOF*
}

Department of Optometry \& Visual Science, International Islamic University Malaysia, Malaysia

('Corresponding author's e-mail: yfirdaus@iium.edu.my)

Received: 22 November 2019, Revised: 23 March 2020, Accepted: 24 April 2020

\begin{abstract}
Purpose: To study the relationship between intraocular pressure (IOP), posture, and central corneal thickness (CCT) among healthy Malays. Method: Thirty-four young adults had their IOPs measured using a handheld tonometer (Accutome, Pennsylvania, USA) after maintaining $5 \mathrm{~min}$ at four different postures; sitting upright, supine, supine $\& 45^{\circ}$ inclination, and prone positions. The sequences of the postures were made random. CCT was measured using Oculus Pentacam (Oculus, Wetzlar, Germany), and the value at the corneal apex was taken. Participants were grouped into Group A with CCT of $<550 \mu \mathrm{m}$, and Group B of $>550 \mu \mathrm{m}$. Results: The highest IOP was recorded at the prone position $23.77 \pm 2.71 \mathrm{mmHg}(\mathrm{p}<0.001)$, and the lowest was at sitting upright $15.43 \pm 2.67 \mathrm{mmHg}(\mathrm{p}<0.001)$. IOP at the supine position was $17.31 \pm 3.07 \mathrm{mmHg}$, and at the supine \& $45^{\circ}$ inclination position was $16.00 \pm 2.80 \mathrm{mmHg}$. IOPs were significantly different between sitting upright and supine $(\mathrm{p}=0.03)$, between sitting upright and prone $(\mathrm{p}$ $<0.001)$, between supine and prone $(\mathrm{p}<0.001)$, and between supine $\&$ inclined $45^{\circ}$ and prone $(\mathrm{p}<$ 0.001). There was no significant difference in IOPs between Group A and Group B at different postures $(p>0.05)$. Conclusions: Change in body posture significantly affects IOP, with the lowest IOP during the sitting upright position, and the highest at the prone position. IOP change upon posture shifts was not affected by CCT.
\end{abstract}

Keywords: Intraocular pressure, Postural change, Central corneal thickness, Healthy Malays, Body Posture

\section{Introduction}

Intraocular pressure (IOP) is defined by the pressure inside the eyeball resulting from aqueous humour production and drainage [1]. The distribution of IOP is normally between 10 to $22 \mathrm{mmHg}$. The older population has been shown to have higher IOP compared to the younger population [1-3], which may be related to the reduction in the efficacy of aqueous drainage. The time of measurement also affects IOP value, as it was shown to be higher in the mornings compared to evenings [4,5], inherent to the diurnal variability of the IOP. Other factors affecting IOP may include water consumption $[4,6]$, accommodation [7-9], body posture [2,3,5], and central corneal thickness (CCT) [10,11].

IOP has been demonstrated to be altered with the change of body posture [2,12] and, interestingly, to be exaggerated at night time [4-6]. A change in posture from the upright position to the supine causes IOP to increase $[12,13]$ due to the body's fluid distribution and hydrostatic responses to episcleral venous pressure $[3,4,14]$. It was demonstrated that IOP is the highest at the prone position, in comparison to the supine position [15]. On the contrary, the routine IOP measurement of upright-sitting was found to be the lowest IOP value in comparison to other postures, which includes supine as well as supine with head 
http://wjst.wu.ac.th

elevated by $45^{\circ}[2,3,5]$. Taking the effect of body posture to the IOP into account is paramount, especially upon the realization that posture during sleeping may cause harmful effects to patients that are predisposed to IOP issues. It is noted that the IOP changes in eyes with glaucoma were reported to be larger in comparison to healthy eyes $[3,4,13]$. Nevertheless, posture change effect on IOP, taking into consideration the effect of CCT, has yet to be elucidated.

CCT plays an important role in determining the accuracy of IOP measurement [16]. This is because falsely high IOP values tend to happen to patients with thicker CCT [17-20] and falsely low IOP may be measured in patients with thinner CCT [16,21]. Studies have shown that CCT influences IOP measurement, especially of those measured using Goldmann Applanation Tonometer (GAT) [22]. This observation can be explained by the area of contact of the tonometer and the corneal surface, which gives effect to the amount of pressure needed to applanate the cornea for an IOP reading. On the other hand, some studies have reported that the tonopen is least affected by this factor $[15,17,22]$. The reduced applanation area of the tonopen, i.e., $2.36 \mathrm{~mm}^{2}$, compared to that of GAT, $7.35 \mathrm{~mm}^{2}$, reduces the difference between IOP and applanation pressure [22]. This causes the reading taken using the tonopen to be lower, but probably truer, than that measured by the GAT on a thicker or thinner CCT $[10,11,22,23]$. Additionally, the tonopen's operation is based on the McKay-Marg principle, whereby it is thought to be unaffected by abnormalities of the corneal surface [22,23]. Nevertheless, the IOP effects on CCT, measured at different postures, are yet to be studied.

Although a number of studies have looked at different postures and theirs effect on IOP $[2,5,6]$, interestingly, the relationship between postural changes and IOP, and the effect of CCT, has not been investigated. This study was conducted to study the difference in IOP at different postures, taking into consideration the CCT, among the healthy Malay population, the largest race in Malaysia.

\section{Materials and methods}

This cross-sectional study was conducted on 2 groups of 34 participants divided based on their CCT profiles. The sample size was calculated based on the study by Chiquet et al. [24] with the $\alpha$ value chosen to be 0.05 for $95 \%$ confidence interval and $\beta$ at 0.20 for $80 \%$ power. Ethical clearance was obtained from the International Islamic University Malaysia (IIUM) Research Ethics Committee.

Participants of Malay descent aged 18 - 40 years old were recruited. All participants were briefed and informed about the study and the procedures involved. Written consents were obtained, adhering to tenets in the Declaration of Helsinki. Inclusion criteria included refractive error range of 0.00 to -2.00 DS, and the cessation of wearing contact lens for at least 1 week. Exclusion criteria included being an alcohol consumer or smoker, having glaucoma or any other ocular diseases, possessing a narrow anterior chamber angle, being hypertensive, being on corticosteroids, or having undergone refractive surgery. Only 1 eye was measured on each participant and those chosen were random by using the Research Randomizer website at randomizer.org. The chosen eye was measured throughout all postures.

CCT was measured first using the pachymetry function of the non-contact Oculus Pentacam (Oculus, Wetzlar, Germany). The CCT at the apex location was taken into analysis. Participants were dichotomized into two groups based on their CCT values; Group A with CCT $<550 \mu \mathrm{m}$, and Group B with $>550 \mu \mathrm{m}$. The value $550 \mu \mathrm{m}$ was set as the middle line following the average normal population CCT value reported by Hoffmann et al. [25] and Muhsen et al. [26]. The IOPs were measured using handheld tonometers (Accutome, Pennsylvania, USA) due to their flexibility to measure IOP at different postures, and their minimal effect on CCT. All participants were made to acclimatize for each posture for $5 \mathrm{~min}$ before each measurement, to stabilize the IOP and for the effect of the previous applanation to be eliminated [1]. Four postures, (i) sitting upright, (ii) supine, (iii) supine \& inclined $45^{\circ}$, and (iv) prone, were chosen in a random order using randomizer software. A drop of proparacaine hydrochloride $0.5 \%$ (Alcaine, Alcon, Texas) was administered on the chosen eye before IOP measurement to numb the cornea. Three readings were taken in each posture and the average value was used for analysis. IOP measurements were taken between 9.00 a.m. to 12.00 p.m. to avoid diurnal fluctuation influences. 
Normality of data was tested using the Shapiro-Wilk test. One-way analysis of variation followed by Tukey post-hoc test was used to compare the IOPs at different postures. Paired t-test was used to compare IOPs between groups of different CCTs.

\section{Results and discussion}

There were 14 male participants recruited in this study. The average age was $21.8 \pm 1.3$ years and the average refractive error was $-0.45 \pm 0.64 \mathrm{DS}$. The average CCT for all participants was recorded as $541 \pm 30 \mu \mathrm{m}$. The highest IOP was obtained at the prone position $(23.77 \pm 2.72 \mathrm{mmHg})$, while the lowest mean IOP was at the sitting upright position $(15.42 \pm 2.67 \mathrm{mmHg})$. The supine position recorded an average of $17.31 \pm 3.07 \mathrm{mmHg}$, while the supine \& inclined $45^{\circ}$ position recorded an average of $16.00 \pm 2.80 \mathrm{mmHg}$. The IOPs between postures were significantly different (one way ANOVA, p < $0.001)$ Table 1 summarizes the IOPs of all participants at different postures.

Table 1 IOPs at different postures for all participants. P-value is indicated upon comparison between postures using one-way ANOVA.

\begin{tabular}{lcc}
\multicolumn{1}{c}{ Posture } & IOP $(\mathbf{m m H g})$ & p \\
& Mean \pm SD & One-way ANOVA \\
\hline Sitting upright & $15.43 \pm 2.67$ & \\
Supine & $17.31 \pm 3.07$ & $<0.001$ \\
Supine \& inclined $45^{\circ}$ & $16.00 \pm 2.80$ & \\
Prone & $23.77 \pm 2.72$ & \\
\hline
\end{tabular}

Tukey post-hoc analysis showed significant difference between sitting upright and supine $(\mathrm{p}=$ $0.030)$, sitting upright and prone $(\mathrm{p}<0.001)$, supine and prone $(\mathrm{p}<0.001)$, and supine $\&$ inclined $45^{\circ}$ and prone $(\mathrm{p}<0.001)$. No significant difference was found between sitting upright and supine $\&$ inclined $45^{\circ}$ $(\mathrm{p}=0.831)$ and supine and supine $\&$ inclined $45^{\circ}(\mathrm{p}=0.212)$. Figure 1 exhibits the IOPs at different postures and the significant pairs. 
http://wjst.wu.ac.th

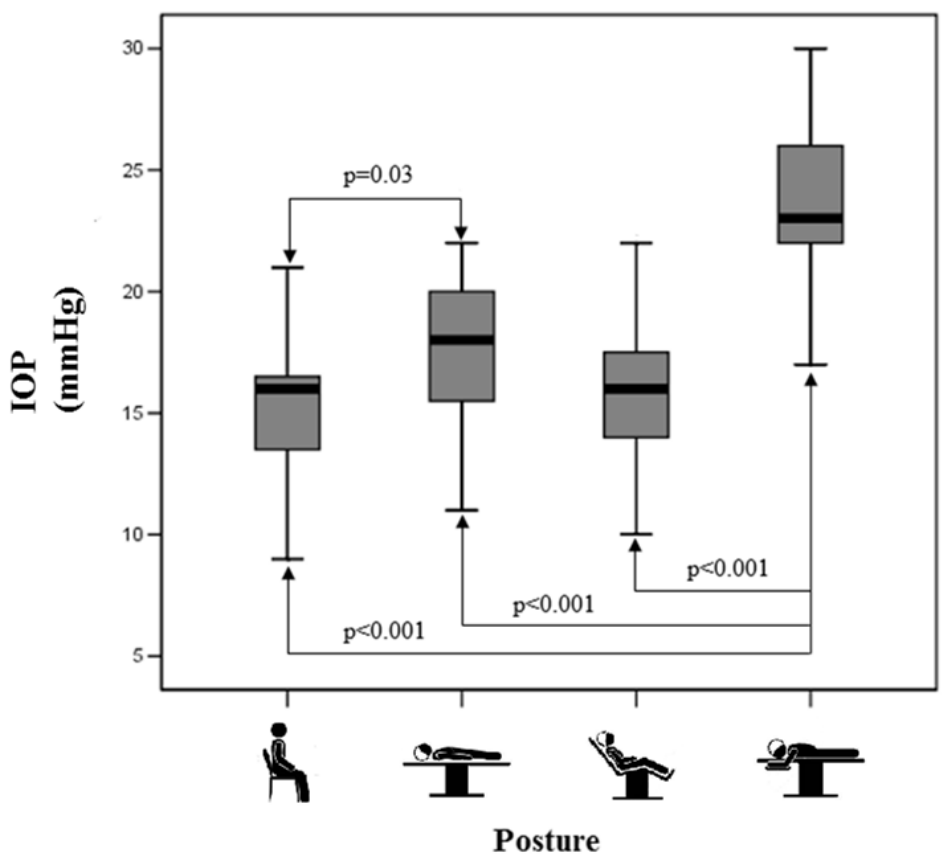

Figure 1 IOPs at different postures. The p-value indicates significant difference between pairs as calculated using Tukey post-hoc test.

Group A had a mean CCT of $521.5 \pm 21.4 \mu \mathrm{m}$, while Group B had a mean CCT of $570 \pm 12.5 \mu \mathrm{m}$ $(p<0.001)$. There was no significant difference in terms of age $(p=0.437)$ or refractive error $(p=0.290)$ between the 2 groups. There was no significant difference in IOPs measured at different postures between Group A and Group B ( $\mathrm{p}>0.05)$. Table 2 and Figure 2 depict the mean IOP between the 2 groups.

Table 2 IOPs at different postures of Group A (CCT of $<550 \mu \mathrm{m})$ and Group B (CCT $>550 \mu \mathrm{m})$. $\mathrm{P}$ values are indicated upon comparison between groups using the independent t-test.

\begin{tabular}{lccc}
\hline & \multicolumn{2}{c}{ IOP (mmHg) } & \\
\cline { 2 - 3 } \multicolumn{1}{c}{ Posture } & Group A & Group B & p (independent \\
& $\mathbf{N}=\mathbf{2 0}$ & $\mathbf{N}=\mathbf{1 4}$ & $\begin{array}{c}\text { t-test) } \\
\end{array}$ \\
\cline { 2 - 3 } & (Mean $\pm \mathbf{S D})$ & (Mean \pm SD) & \\
\hline Sitting upright & $15.5 \pm 2.5$ & $15.3 \pm 3.0$ & 0.800 \\
Supine & $17.3 \pm 2.8$ & $17.4 \pm 3.5$ & 0.947 \\
Supine \& inclined 45 & $16.1 \pm 2.5$ & $15.8 \pm 3.3$ & 0.717 \\
Prone & $23.9 \pm 2.3$ & $23.6 \pm 3.3$ & 0.728 \\
\hline
\end{tabular}




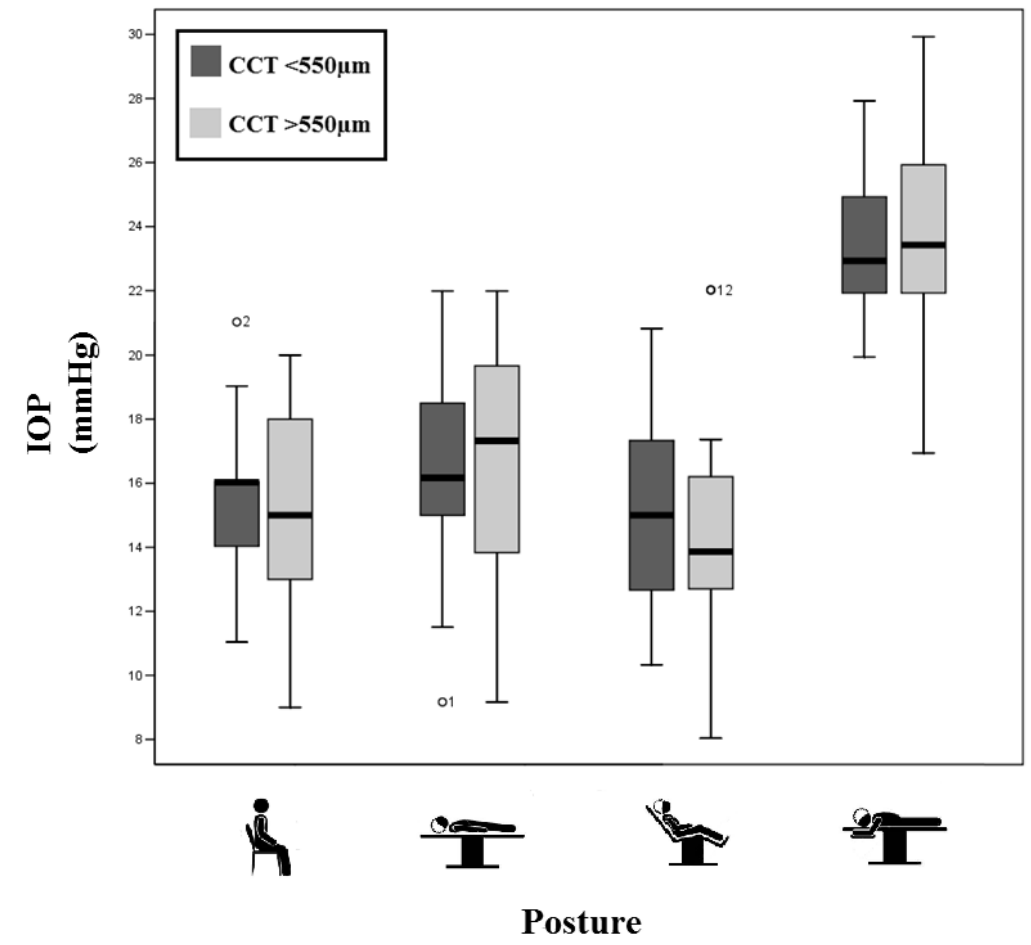

Figure 2 IOPs at different postures for both groups. The IOPs for each posture were not different between groups, indicated by independent t-test. Both groups showed the same IOP trend for all postures.

\section{Relationship between IOP and posture}

Our findings were in concert with other studies which showed that IOP in the sitting position is lower than in the supine position [2,3,15,27,28,29] and increases further during the prone position $[2,15,27]$. In general, IOP is higher when the position of the eye is lower than the heart [30], and even higher upon association with gravity [5]. Malihi and Sit [2] reported a range of 0.3 to $5.6 \mathrm{mmHg}$ difference between the sitting IOP and the supine IOP in both normal and glaucomatous subjects. Prata et al. [31] reported that the degree of IOP change (relative from the primary position, sitting) depends on the angle of body tilt and the duration of exposure (length of time whereby the subject is maintained in a particular position) [31]. They also reported a threefold increase in IOP with complete inversion of gravity [31].

In our study, there was no significant difference in IOP between sitting upright and supine \& inclined $45^{\circ}(\mathrm{p}=0.831)$ and between supine and supine $\&$ inclined $45^{\circ}(\mathrm{p}=0.212)$. However, Buys et al. [32] and Beltran-Agullo et al. [14] reported significant increase in IOP at the supine position compared to the $30^{\circ}$ head-up position. Our findings may differ due to the 15 degree difference of head elevation.

The possible explanation of IOP changes following postural change have been postulated in a few studies $[30,33,34]$. It was found that an increment in episcleral venous pressure creates an obstruction to the aqueous outflow during posture change [34]. Upon elevation of episcleral venous pressure, transient congestion of ocular tissues may occur [5]. The choroid, being the most vascularized ocular tissue, may expand due to this congestion, changing the dynamics of the ocular fluid, causing the IOP to increase [5]. It was also mentioned in one study that, for each $0.83 \mathrm{mmHg}$ increase in episcleral venous pressure, $1 \mathrm{mmHg}$ increase in IOP was noted [5]. The episcleral venous pressure depends on the position of the eyes relative to the heart [30]. When standing up or sitting upright, the eye is $30 \mathrm{~cm}$ above the heart [33]. However, when being in the supine position, the eyes and heart are almost at the same level, hence 
http://wjst.wu.ac.th

increasing the episcleral venous pressure relative to the value during a standing position. This leads to a higher IOP when the eyes are at the same level or lower than the heart.

Alternatively, the immediate increase in IOP upon changing to the supine position may be caused by a sudden uveal blood flow increment [33]. Increased aqueous outflow resistance or increased aqueous production may be the cause of the sustained rise in the IOP [30]. There are many interconnections between the orbital drainage routes and the lack of venous valve in the orbit [33] which leads to resistance in aqueous flow and causes IOP in the supine position to be higher [33]. Nevertheless, the response of IOP to posture change differs individually, whereby IOP change cannot be predicted based on the IOP during sitting upright, both in healthy and glaucomatous individuals [30,35].

Upon comparison of IOP during sitting upright, the IOP when in the supine position is relatively higher, as reported in a number of studies [2,30]. We recorded the same response in our study, with IOP values rising nearly $2 \mathrm{mmHg}$ in the supine position relative from the sitting posture. Along the same lines to our findings, Ozcan et al. [27] reported a significantly higher IOP in the prone position $(20.3 \mathrm{mmHg})$ relative to the supine position $(16.8 \mathrm{mmHg}$ ) [27]. We saw an increment of $6 \mathrm{mmHg}$ in IOP at the prone position relative to the supine position, and $8 \mathrm{mmHg}$ relative to the sitting position.

\section{Relationship between IOP, posture, and CCT}

We reported no significant difference in mean IOP between participants of differing CCTs at all postures $(p>0.05)$. The usage of tonopen in this study eliminates the possible bias of tonometry by the factor of CCT. We ensured that the IOP values were true IOPs, without measurement bias affected by CCT. Hence, the insignificant IOP difference within each posture that we have reported indicates that CCT does not play a part in IOP-posture relationship. This observation also emphasizes the feasibility of tonopen in eliminating measurement bias from the confounding factor of CCT. Bhan et al. [22] in their study on 181 normal eyes reported an insignificant difference in IOP between groups of differing CCT, taken in the sitting posture. The same findings were reported by Mok et al. [16] in their studies on 48 normal eyes taken upon participants in the sitting upright posture. Both studies used tonopen as a mean of tonometry. It is noted that our study may be the first to compare the IOP-postural effect taking CCT into consideration among Malay eyes.

This study was conducted on young and healthy groups of individuals of Malay descent. Results may vary if the same study variables were conducted on older subjects or those with ocular hypertension and glaucoma, or of different races. Recent studies by Park et al. [36] found no significant difference in IOP between 2 eyes at different positions. Further research regarding IOP between 2 eyes at different postures should be conducted in detail.

Some increment in CCT was seen in participants who randomly re-measured their CCT for another study on the same day. This CCT thickening, possibly oedema, was probably due to the repeated usage of topical anesthetics, Future studies should attempt to use an instrument that does not need local anesthetics or be non-contact in nature to give a better result, depending on the accuracy of the instrument. Nevertheless, considering the involvement of changing body positions in this study, the non-contact IOP measurement method needs to be robust and ideal following different positions.

\section{Conclusions}

Change in body posture has significant effect on IOP, with the lowest IOP during the sitting upright position, and the highest at the prone position. Therefore, individuals who are at risk of having glaucoma or who already have glaucoma should avoid postures or activities that could encourage a spike in their IOP. IOP change upon posture shifts was not affected by the CCT. The usage of tonopen, which is not affected by CCT, eliminated the possible bias that could influence the measurement of IOP.

\section{Acknowledgements}

This study was supported by the Research Management Centre, International Islamic University Malaysia, under the Research Initiatives Grant Scheme (RIGS) - Publication (P-RIGS 16-127-0291). 


\section{References}

[1] M Millodot. Dictionary of optometry and visual science. $5^{\text {th }}$ eds. Butterworth Heinemann, Great Britain. 2002, p. 368.

[2] M Malihi and AJ Sit. Effect of head and body posture on intraocular pressure. J. Ophthalmol. 2012; 119, 987-91.

[3] JHK Liu, RP Bouligny, DF Kripke and RN Weinreb. Nocturnal elevation of intraocular pressure is detectable in the sitting position. Investig. Ophthalmol. Vis. Sci. 2003; 44, 4439-42.

[4] M Hatanaka, LM Sakata, R Sussana, LTF Nascimento and M Vessani. Comparison of the intraocular pressure variation provoked by postural change and by the water drinking test in primary open-angle glaucoma and normal patients. J. Glaucoma 2016; 25, 914-8.

[5] RB Patil, V Pai and KP Hudedagaddi. To study the effect of postural changes in intraocular pressure and its importance in glaucoma control. J. Evid. Based. Med. Health 2015; 2, 2303-7.

[6] CWK Chong, SB Wang, NS Jain, CS Bank, R Singh, A Bank, IC Francis and A Agar. Clin. Exp. Ophthalmol. 2016; 44, 768-75.

[7] F Jenssen and J Krohn. Effects of static accommodation versus repeated accommodation on IOP. $J$. Glaucoma 2012; 21, 45-8.

[8] GK Rai, B Gilmartin, JS Wolffsohn and A Cervino. The effect of accommodation on IOP: Evidence for dose dependency. Inv. Ophthalmol. Vis. Sci. 2006; 47, 5859.

[9] Y Liu, H Lv, X Jiang, X Hu, M Zhang and X Li. Intraocular pressure changes during accommodation in progressing myopes, stable myopes and emmetropes. PLoS One 2015; 10, 1-10.

[10] J Jethani, P Dave, M Jethani, Y Desai and P Patel. The applicability of correction factor for corneal thickness on non-contact tonometer measured intraocular pressure in LASIK treated eyes. Saudi. J. Ophthalmol. 2016; 30, 25-8.

[11] BA Francis, R Varma, V Chopra, MY Lai, C Shtir, SP Azen and Los Angeles Latino Eye Study Group. Intraocular pressure, central corneal thickness and prevalence of open-angle glaucoma: The Los Angeles Latino eye study. Am. J. Ophthalmol. 2008; 146, 741-6.

[12] H Mayali, B Tekin, OR Kayikcioglu, E Kurt and SS Ilker. Evaluation of the effect of body position on intraocular pressure measured with rebound tonometer. Turk. J. Ophthalmol. 2019; 49, 6-9.

[13] N Gautam, S Kaur, S Kaushik, S Raj and SS Pandav. Postural and diurnal fluctuations in intraocular pressure across the spectrum of glaucoma. Br. J. Ophthalmol. 2016; 100, 537-41.

[14] L Beltran-Agullo, YM Buys, F Jahan, CM Shapiro, JG Flanagan, J Cheng and GE Trope. Twentyfour hour intraocular pressure monitoring with the SENSIMED Triggerfish contact lens: Effect of body posture during sleep. Br. J. Ophthalmol. 2017; 101, 1323-8.

[15] A Lam, YF Wu, LY Wong and NL Ho. IOP Variations from sitting to supine postures determined by rebound tonometer. J. Optom. 2013; 5, 95-100.

[16] KH Mok, CS Wong and VW Lee. Tono-pen tonometer and corneal thickness. Eye (Lone) 1999; 13, 35-7.

[17] PA Tonnu, T Ho, T Newson, A El Sheikh, K Sharma, E White, C Bunce and D Garway-Heath. The influence of central corneal thickness by pneumotonometry, non-contact tonometry, the tono-pen XL and Goldmann applanation tonometry. Br. J. Ophthalmol. 2005; 89, 851-4.

[18] WA Argus. Ocular hypertension and central corneal thickness. J. Ophthalmol. 1995; 102, 1810-2.

[19] LW Herndon, SA Choudri, T Cox, KF Damji, MB Sheilds and R Allingham. Central corneal thickness in normal, glaucomatous and ocular hypertensive eyes. Arch. Ophthalmol. 1997; 124, 165-8.

[20] RCW Wolfs, CCW Klaver, JR Vingerling, DE Grobbee, A Hofman and PTVM Dejong. Distribution of central corneal thickness and its association with intraocular pressure: The Rotterdam study. Am. J. Ophthalmol. 1997; 123, 767-72.

[21] A Chatterjee, S Shah, DA Bessant, SA Naroo and SJ Doyle. Reduction in intraocular pressure after excimer laser photorefractive keratectomy. J. Ophthalmol. 1997; 104; 355-9.

[22] A Bhan, AC Browning, S Shah, R Hamilton, D Dave and HS Dua. Effect of corneal thickness on intraocular pressure measurements with the pneumotonometer, Goldmann applanation tonometer and tono-pen. Investig. Ophthalmol. Vis. Sci. 2002; 43, 1389-92. 
[23] T Huseynova, GO Waring, C Roberts, RD Krueger and M Tomita. Corneal biomechanics as a function of intraocular pressure and pachymetry by dynamic infrared signal and Schiempflug imaging analysis in normal eyes. Am. J. Ophthalmol. 2014; 157, 885-93.

[24] C Chiquet, M Custaud, A Pavy Le Travon, C Millet, C Gharib and P Dennis. Changes in intraocular pressure during prolonged (7-day) head down tilt bedrest. J. Glaucoma 2003; 12, 204-8.

[25] EM Hoffmann, J Lamparter, A Mirshahi, H Elflein, R Hoehn, C Wolfram, K Lorenz, M Adler, PS Wild, A Schulz, B Mathes, M Blettner and N Pfeiffer. Distribution of central corneal thickness and its association with ocular parameters in a large Central European Cohort: The Gutenberg study. PLoS One 2013; 8, e66158.

[26] S Muhsen, F Alkhalaileh, M Hamdan and SA AlRyalat. Central corneal thickness in a Jordanian population and its association with different types of Glaucoma: Cross-sectional study. BMC Ophthalmol. 2018; 18, 1-7.

[27] MS Ozcan, C Praetel, MT Bhatti, N Gravenstein, ME Mahla and CN Seubert. The effect of body inclination during prone positioning on intraocular pressure in awake volunteers: A comparison of two operating tables. Anesth. Analg. 2004; 99, 1152-8.

[28] DW Evans, A Harris, SC Hak and L Kagemann. Glaucoma patients demonstrate faulty autoregulation of ocular blood flow during posture change. Br. J. Ophthalmol. 1999; 83, 809-13.

[29] D Selvadurai, D Hodge and AJ Sit. Aqueous humour outflow facility by tonography does not change with body position. Investig. Ophthalmol. Vis. Sci. 2010; 51, 1453-7.

[30] R Hiller, RD Sperduto and DE Krueger. Race, iris pigmentation and intraocular pressure. Am. J. Epidemiol. 1981; 115, 674-83.

[31] TS Prata, CGV De Moraes, FN Kanadani, R Ritch and A Paranhos. Posture-induced intraocular pressure changes. Surv. Ophthalmol. 2010; 55, 445-53.

[32] YM Buys, T Alasbali, YP Jin, M Smith, P Gouws, N Geffen, JG Flanagan, CM Shapiro and GE Trope. Effect of sleeping in a head-up position on intraocular pressure in patients with glaucoma. Ophthalmol. 2010; 117, 1348-51.

[33] T Hara, T Hara and T Tsuru. Increase of peak intraocular pressure during sleep in reproduced diurnal changes by posture. Arch. Ophthalmol. 2006; 115, 1137-41.

[34] AKC Lam and WA Douthwaite. The effect of an artificially elevated intraocular pressure on the central corneal curvature. Ophthal. Physl. Opt. 1997; 17, 18-24.

[35] AC Kothe. The effect of posture on intraocular pressure and pulsatile ocular blood flow in normal and glaucomatous eyes. Surv. Ophthalmol. 1994; 38, S191-S197.

[36] J Park, C Yoo, K Yang and YY Kim. Effect of different body postures on the intraocular pressure in patients with primary angle-closure disease. Optom. Vis. Sci. 2019; 96, 477-83. 